\title{
PARTICIPAÇÃO POPULAR E A EXECUÇÃO FINANCEIRA E ORÇAMENTÁRIA, SOB A PERSPECTIVA DA LEI DE RESPONSABILIDADE FISCAL
}

\author{
Waleska Gabriely Almeida ${ }^{1}$ \\ Magno Alves Ribeiro ${ }^{2}$ \\ Vanderleia Aparecida da Silva ${ }^{3}$ \\ Josiani Silva Costa ${ }^{4}$
}

\begin{abstract}
RESUMO
O estudo teve como finalidade, identificar a divulgação das informações nos meios eletrônicos, sobre a participação popular nas audiências públicas e a execução financeira e orçamentária, no município de Tangará da Serra - MT, para verificar se atende a Lei de Responsabilidade Fiscal no que diz respeito à transparência pública. Consiste em um estudo documental, visto que foram analisados os anexos sobre receitas e despesas, e atas de audiências públicas. Pesquisa de abordagem quantitativa, natureza descritiva e coleta de dados realizada por meio de acesso à internet no site da prefeitura. Os resultados evidenciam que o município atende parcialmente o que a Lei de Responsabilidade Fiscal determina, haja vista que as publicações estão disponíveis, porém, não estão de fácil acesso, falta clareza nas informações e não são disponíveis em tempo real.
\end{abstract}

Palavras-chave: Informação. Sociedade. Governo. Transparência.

\begin{abstract}
This study intented to identify the divelgation of informations in electronic media on popular participation in public hearings and financial and budgetary execution in Tangará Serra - MT municipality that verified if it attends the Fiscal Responsibility Law (Lei de Responsabilidade Fiscal) about public transparency. It consists a document study which analyzed the annexes about revenues, expenses and public audiences records. Quantitative approach research with descriptive kind and data collection done by internet access on the city hall site. The results shows that the municipality partially attends what the Fiscal Responsibility law determines since the publications are available but not in easy access, with lacks of clear information, not available in real time.
\end{abstract}

Keywords: Information. Society. Government. Transparency.

\section{INTRODUÇÃO}

A Transparência Pública, participação popular e o acesso à informação estão previstas na Constituição Federal, no inciso XXXIII do art. $5^{\circ}$, no inciso II do $\S 3^{\circ}$ do art. 37 e no $\S 2^{\circ}$ do art. 216 (BRASIL, 1988). A Transparência Pública da gestão fiscal é regulamentada pela Lei de Responsabilidade Fiscal (LRF) $n^{\circ} 101$ de maio de 2000, juntamente com a lei

\footnotetext{
${ }^{1}$ Universidade do Estado de Mato Grosso (UNEMAT), Acadêmica Curso Ciências Contábeis.

${ }^{2}$ Universidade do Estado de Mato Grosso (UNEMAT), Professor Mestre Departamento Contabilidade.

${ }^{3}$ Universidade do Estado de Mato Grosso (UNEMAT), Professora do Departamento de Ciências Contábeis.

${ }^{4}$ Universidade do Estado de Mato Grosso (UNEMAT), Professora do Departamento de Ciências Contábeis. 
complementar $\mathrm{n}^{\circ} 103$ de maio de 2009 e o acesso a informação pela lei $\mathrm{n}^{\circ} 12.527$ de novembro de 2011.

A LRF dedica uma seção que trata apenas da Transparência na gestão fiscal dentro do capítulo da Transparência, controle e fiscalização, a qual menciona os conceitos de transparência e participação. Entretanto, com a lei complementar $n^{\circ} 131$, de 27 de maio de 2009 aprimorou-se a interação da sociedade em relação ao setor público, desta forma, prevê o controle social e a transparência pública, ao dispor que a Transparência está assegurada mediante: incentivo à participação popular e realização de audiências públicas, durante os processos de elaboração e discussão dos planos, lei de diretrizes orçamentárias e orçamentos; liberação ao pleno conhecimento e acompanhamento da sociedade, em tempo real as informações pormenorizadas sobre a execução orçamentária e financeira, em meios eletrônicos de acesso público (EVANGELISTA; MOTA, 2010).

De acordo com Nascimento e Debus (2001), a LRF propõe de fato reforçar o papel da atividade de planejamento e a vinculação entre as atividades de planejamento e de execução do gasto público, e a transparência será alcançada através do conhecimento e da participação da sociedade, assim como na publicidade das informações de atos e fatos ligados à arrecadação de receitas e à realização de despesas pelo poder público. Com isso, tem-se a problemática de verificar a efetiva divulgação das informações estabelecidas por lei nos meios de acesso público do município de Tangará da Serra.

A partir desse Princípio, este estudo tem como objetivo geral identificar a divulgação das informações nos meios eletrônico do município. E os objetivos específicos são: Analisar as divulgações das informações sobre receitas e despesas pública por meio das publicações na página eletrônica da Prefeitura; Verificar os relatórios e atas de participantes nas audiências públicas durante os processos de elaboração e discussão dos planos, lei de diretrizes orçamentárias e orçamentos.

Justifica-se por não haver estudo detalhado no município de Tangará da Serra - MT, que proponha identificar, acompanhar e analisar as informações, que é dever do município disponibilizá-los aos cidadãos para que possam acompanhar e ficarem informados sobre o destino dos recursos que por eles são financiados. Pois, tal conhecimento faz-se necessário, para que a sociedade possa exigir maior desempenho e melhorias do governo, e avaliar a eficiência na administração dos recursos. 


\subsection{Transparência Pública}

Na Transparência Pública, existem instrumentos de gestão fiscal, que por meio deles pode-se ter acesso às informações como orçamentos, prestações de contas, leis de diretrizes orçamentárias, relatório de execução do orçamento e relatório de gestão fiscal, por isso, devem ser publicados por meios eletrônicos gratuitos (BRASIL, 2000). A Transparência na gestão pública é substanciada na divulgação periódica de relatórios, realização de audiências públicas regulares, na prestação de contas dos chefes dos poderes, e há como base três características: publicidade, compreensibilidade e utilidade, pois de nada adianta divulgar as

informações se não for de forma amplas, clara e de linguagem acessível (GUADAGNIN, 2011).

Definido pela lei complementar $n^{\circ} 131 / 2009$, todos os entes têm obrigação de divulgar, para fins de conhecimento e acompanhamento da sociedade, essas informações. Neste contexto, elas precisam estar disponíveis na internet, não obrigatório no Portal da Transparência, mas de preferência que seja, para que se concentrem todas as informações em um só local, de modo que facilite o acesso (PORTAL DA TRANSPARÊNCIA, 2015e).

Os Princípios gerais da Transparência pública são: publicidade e sigilo, e a informação deve ser de forma ágil, transparente, clara e de fácil compreensão, e as divulgações das informações devem ser publicadas independe de solicitações, e a gestão da informação deve ser transparente e de amplo acesso (CONTROLADORIA GERAL DA UNIÃO, 2012).

A LRF que tem como finalidade primordial formular regras de finanças públicas para a responsabilidade da gestão fiscal, instituiu o planejamento e a Transparência, portanto, é relevante ressaltar que a sua abrangência é nacional, ou seja, é regra para todas as esferas de governo, isto é, União, Estados, Distrito Federal e Municípios; para os três poderes, Executivo, Legislativo e Judiciário, assim como para o Ministério Público; e todos os órgãos e entidades pertencentes à administração pública, sendo administração direta, fundos, autarquias, fundações e empresas estatais dependentes (CULAU; FORTIS, 2006).

O estímulo a transparência pública é objetivo primordial da moderna Administração 
Pública, extensa e relevante divulgações das ações do governo a milhões de brasileiros, que contribuem para o fortalecimento da democracia e desenvolvem ações de cidadania, desde modo, conforme a Portaria $\mathrm{n}^{\circ} 140$ de março de 2006, cada órgão e entidade deve ter sua própria página de Transparência com informações detalhadas (CONTRALODORIA GERAL DA UNIÃO, 2015).

\subsubsection{Portal da Transparência}

Lançada no mês de novembro de 2004, o Portal da Transparência do Governo Federal é uma iniciativa da Controladoria Geral da União (CGU). É o Órgão do Governo Federal, responsável pela fiscalização dos recursos federais repassados aos estados, municípios e cidadãos beneficiados por meio de programas do Governo. Seu objetivo é evidenciar a transparência da gestão pública, para que os cidadãos acompanhem e auxiliem a fiscalizar, assim assegurar a boa e correta aplicação dos recursos públicos. É de conhecimento de todos que o Estado Brasileiro tem grande número de municípios, portanto, a CGU precisa da participação de toda sociedade no controle dos recursos para que seja realizado de forma mais eficaz (PORTAL DA TRANSPARÊNCIA, 2015g).

Quanto aos dados disponibilizados no Portal da Transparência são de responsabilidade dos ministérios e outros órgãos do Poder Executivo Federal, por serem eles os executores dos programas de governo e os responsáveis pela gestão das ações governamentais. A CGU reúne e disponibiliza informações sobre a aplicação dos recursos federais no Portal da Transparência, até na data de 20 de maio de 2015 já tinham sido divulgados um total de 1.954.426.856 dados, que geram informações quanto as despesas, receitas, convênios, empresas sancionadas, servidores, cadastro de entidades privadas sem fins lucrativos impedidas, imóveis funcionais, beneficiários da lei 10.559/2002 e grandes eventos, como a Copa do Mundo de 2014 e a Olímpiadas de 2016 (PORTAL DA TRANSPARÊNCIA, 2015a).

As figuras a seguir, são referentes às estatísticas de acesso ao portal da transparência desde a sua criação até ao mês de abril 2015, em números e em quadro para melhor compreensão.

Quadro 1 - Estatística de acesso ao Portal da Transparência. 


\begin{tabular}{|c|c|c|c|c|c|c|c|c|c|c|c|c|}
\hline & \multicolumn{12}{|c|}{ Visitas } \\
\hline Mês/Ano & 2015 & 2014 & 2013 & 2012 & 2011 & 2010 & 2009 & 2008 & 2007 & 2006 & 2005 & 2004 \\
\hline Janeiro & 1.360 .853 & 1.127 .459 & 710.222 & 313.136 & 221.671 & 195.659 & 106.628 & 91.548 & 48.799 & 20.354 & 15.945 & - \\
\hline Fevereiro & \begin{tabular}{|l|}
1.169 .802 \\
\end{tabular} & 1.040 .480 & 615.777 & 286.260 & 220.643 & 188.106 & 96.499 & 152.867 & 48.874 & 19.072 & 10.561 & - \\
\hline Março & \begin{tabular}{|l|}
1.418 .862 \\
\end{tabular} & 1.119 .631 & 738.665 & 410.141 & 254.431 & 247.369 & 131.332 & 109.176 & 59.017 & 24.443 & 12.452 & - \\
\hline Abril & 1.307 .700 & 1.146 .048 & 886.824 & 372.276 & 245.335 & 228.467 & 118.262 & 109.751 & 56.554 & 26.729 & 25.906 & - \\
\hline Maio & & 1.368 .817 & 1.009 .019 & 536.802 & 295.399 & 285.299 & 124.401 & 108.257 & 56.869 & 27.068 & 25.655 & - \\
\hline Junho & & 1.203 .964 & 982.573 & 937.299 & 288.998 & 223.867 & 126.039 & 105.611 & 65.988 & 26.035 & 52.534 & - \\
\hline Julho & & 1.297 .275 & 1.021 .975 & 1.291 .436 & 281.312 & 230.082 & 127.882 & 112.257 & 70.004 & 26.855 & 38.001 & - \\
\hline Agosto & & 1.230 .670 & 1.045 .279 & \begin{tabular}{|l|}
1.163 .608 \\
\end{tabular} & 320.463 & 257.655 & 169.302 & 123.455 & 66.829 & 37.999 & 25.876 & - \\
\hline Setembro & & 1.247 .488 & 945.910 & 812.120 & 308.729 & 361.946 & 181.184 & 126.556 & 45.752 & 40.614 & 19.733 & - \\
\hline Outubro & & 1.315 .369 & 986.774 & 795.427 & 305.453 & 248.316 & 175.652 & 119.441 & 47.431 & 48.164 & 18.830 & - \\
\hline Novembro & & 1.260 .771 & 1.060 .448 & 656.748 & 314.689 & 250.752 & 160.994 & 134.783 & 40.610 & 32.474 & 20.168 & 30.064 \\
\hline Dezembro & & 1.250 .631 & 1.054 .230 & 594.793 & 312.152 & 220.634 & 186.109 & 149.908 & 39.974 & 47.271 & 20.307 & 34.262 \\
\hline Média Mensal & 1.314 .304 & 1.217 .384 & 921.475 & 680.837 & 280.773 & 244.846 & 142.024 & 120.301 & 53.892 & 31.423 & 23.831 & 32.163 \\
\hline tal & 5.257 .217 & 14.608 .603 & 11.057 .696 & 8.170 .046 & 3.369 .275 & 2.93 & .284 & 1.44 & 646.701 & 377.078 & 285.968 & 64.326 \\
\hline
\end{tabular}

Fonte: Portal da Transparência do Governo Federal (2015).

Pode-se visualizar que desde a criação do portal da transparência em 2004, o número de acesso só aumenta, o que sugere interesse da população em relação às ações do governo e acompanhamento das contas públicas.

O portal da transparência exerce a função de instrumento de prestação de contas dos administradores públicos, de modo que incentiva o controle social, para que os cidadãos acompanhem as execuções e ações do governo. E ainda menciona que a LRF determina que as informações apuradas sejam disponibilizadas em meio eletrônico, para que amplie e promova o acesso dos cidadãos via internet, entretanto, a informação ainda que instantânea, precisa ser confiável e ter clareza (CULAU; FORTIS, 2006).

\subsection{Participação Popular}

Compreende como participação popular, o incentivo à participação da sociedade nos processos de elaboração e discussões dos planos de governo em audiência pública (BRASIL, 2000). A participação popular é a base do controle social, e se fortaleceu com as ações da transparência dos entes governamentais e das contas públicas, pois antes as informações não eram amplamente divulgadas, a sociedade não podia acompanhar a gestão dos governos, a LRF é uma das ações que contribui para o processo de transparência da administração pública (FIGUEIREDO; SANTOS, 2013).

Exercer a cidadania é um dos fundamentos da República. Desta forma, é assegurada a população a ter iniciativa em projetos de lei, desde que atendam aos requisitos: direito de petição de assuntos de interesse individual, coletivo ou geral. E também relata a existência de dois instrumentos relevantes: os princípios da administração pública sendo legalidade, impessoalidade, moralidade, publicidade e eficiência e a possibilidade de o cidadão denunciar irregularidades ou ilegalidades ao Tribunal de Contas da União, que conta com um órgão técnico, especializado do Estado para ajudar a sociedade no combate a corrupção e ao desvio 
de dinheiro público (CULAU; FORTIS, 2006).

A participação popular é um Princípio previsto na Constituição Federal de 1988, a situação a qual o cidadão atua no interesse da coletividade, não em interesse individual, o qual visa superar situações pelas vias administrativas ou judiciais. Assim, a sociedade exerce perante a administração pública, o direito de opinar sobre as prioridades, participar, decidir, compartilhar, validar e proteger a aplicação dos recursos públicos na geração de benefícios à coletividade (EVANGELISTA; MOTA, 2010).

A participação popular, assim como o controle social, não são apenas direitos da sociedade, mas, também dever e por isso, é de grande valia que todos fiscalizem os recursos federais repassados aos estados e municípios. Neste interim, cabe a cada cidadão a tarefa de fiscalizar e acompanhar os gastos do Governo Federal, e a correta aplicação do dinheiro público (PORTAL DA TRANSPARÊNCIA, 2015d).

Nas democracias, as quais os cidadãos delegam autoridade para tomada de decisões, a transparência e prestação de contas em conjunto, tem função para produzir a informação de que os cidadãos precisam para avaliarem o valor e as ações dos governos. A participação da sociedade complementa este processo em que o público é visto como o público final na disponibilização das informações fornecidas por meio dos processos de transparência (HARRISON; SAYOGO, 2014).

Os governos democráticos, às vezes, ficam aquém de cumprir a expectativas da sociedade, o que dá origem as exigências de transparência, que tem sido descrita como uma solução para as deficiências e operações de governo, no entanto, poucos cidadãos têm interesse no conhecimento sobre os orçamentos dos governos (HARRISON; SAYOGO, 2014).

\subsubsection{Lei de Diretrizes Orçamentária e Orçamentos}

O modelo orçamentário brasileiro é definido na Constituição Federal de 1988, no art. 165 que estabelece as Leis de iniciativa do Poder Executivo, composta de três instrumentos: o Plano Plurianual (PPA), a Lei de Diretrizes Orçamentárias (LDO) e a Lei Orçamentária Anual (LOA), os quais revestem-se de significativa relevância. O Plano Plurianual é a peça que estabelece os programas e ações de governo por quatro anos; já a Lei de Diretrizes estabelece as prioridades, metas e premissas básicas norteadoras da elaboração do orçamento anual e a Lei Orçamentária Anual à elaboração detalhada da programação a ser realizada em 
determinado exercício financeiro compreendendo $1^{\circ}$ de janeiro a 31 de dezembro (SACRAMENTO, 2005).

\subsubsection{Lei de Diretrizes Orçamentária}

A LDO norteia a elaboração e execução do orçamento anual e aborda outros assuntos como: alterações tributárias, gastos com pessoal, política fiscal e transferências (SENADO FEDERAL, 2015a). Comtempla metas e prioridades da administração pública, compreendendo as despesas de capital para o exercício financeiro seguinte, orienta a elaboração da lei orçamentária anual, trata também das alterações na legislação tributária e ainda estabelece política de aplicação das agências financeiras de fomento (GONTIJO, 2015).

A LRF adicionou atribuições a LDO, que destaca como relevante: competência para dispor sobre critérios e formas de limitação de empenho; competência para o estabelecimento de normas relativas ao controle de custos e a avaliação dos resultados dos programas orçamentários e determinação de inclusão de dois anexos na LDO. O primeiro anexo é o de Metas Fiscais, que trata das metas anuais de receitas, despesas, resultados primário e nominal para o exercício a que se referirem e para os dois seguintes; e o segundo anexo é o de Riscos Fiscais, que tem finalidade de avaliar os passivos contingentes e riscos capazes de afetar as contas públicas (CULAU; FORTIS, 2006).

A LDO é de hierarquia especial, sendo assim, é sujeita a prazos e ritos peculiares de tramitação e tem objetivo de orientar a forma e o conteúdo da LOA de cada exercício. Também estabelece parâmetros para alocação dos recursos no orçamento anual, assim garante a realização das metas e objetivos previstos no PPA, ou seja, a LDO é instrumento de elo entre o PPA e os orçamentos anuais (SALLES, 2012).

\subsubsection{Lei orçamentária Anual}

A LOA estima as receitas que são pretendidas a arrecadar e fixa os gastos, os quais serão financiados com as receitas (SENADO FEDERAL, 2015c). Desta forma, compreende o orçamento fiscal das três esferas de governo, seus fundos, órgãos e entidades da administração direta e indireta; o orçamento de investimento das empresas em que a União, direta ou indiretamente, detenha a maioria do capital social com direito a voto; o orçamento da seguridade social e órgãos a ela vinculados, assim como os fundos e fundações instituídos e mantidos pelo governo (GONTIJO, 2015). 
Salles (2012 p. 83), “a LOA contém a previsão das receitas e a autorização das despesas, a política econômica financeira, o programa de governo e os mecanismos de flexibilidade que a Administração fica autorizada a utilizar para o ano seguinte". Os instrumentos de planejamento e orçamento com as normas fiscais devem ser compatíveis, para tanto, é necessário prevalecer a harmonia entre a LRF e o PPA, LDO e LOA (CULAU; FORTIS, 2006).

\subsubsection{Plano Plurianual}

O PPA trata dos projetos e os programas de longo prazo do governo, definindo, seus objetivos e metas da ação pública referente há quatro anos (SENADO FEDERAL, 2015b). O PPA estabelece as diretrizes, objetivos e metas da administração pública, para as despesas de capital e delas decorrentes, bem como para as relativas aos programas de duração continuada (GONTIJO, 2015).

Em relação aos planos, cabe destacar que o planejamento, assim como a transparência, é um dos pilares da gestão fiscal responsável e que atualmente, o planejamento e a utilização dos recursos públicos são executados por meio do Plano Plurianual (CULAU; FORTES, 2006). O PPA por ser elaborado com um período de vigência de quatro anos, sua gestão e vigência implica no segundo ano do mandato atual ao final do primeiro ano do mandato subsequente. Tem como objetivo garantir a continuidade das ações, por meio dos mandatos, por isso tem como mérito controlar as variações as quais esperamos (SALLES, 2012).

\subsection{Execução orçamentária e Financeira}

Conforme a Brasil (2000), compreende execução orçamentária e financeira, para conhecimento e acompanhamento da sociedade, as receitas e despesas pública. Receita é toda arrecadação de renda autorizada pela Constituição Federal, Leis e Títulos Creditórios à Fazenda Pública; são as entradas que se incorporam ao patrimônio como elemento novo e positivo; são todas as quantias recebidas pelos cofres públicos, e também toda e qualquer entrada de fundo nos cofres do Estado, independentemente de sua origem ou fim (MINISTÉRIO DA FAZENDA, 2015b).

A consulta das receitas no Portal da Transparência permite acompanhar, em detalhes, as previsões e as receitas realizadas do Governo Federal a quem fizer interesse. Encontramse informações referentes a receitas previstas já ajustadas, receitas realizadas e os respectivos 
percentuais de realização, em consulta permite também o detalhamento dos dados apresentados por categoria, origem, espécie, rubrica, alínea e sub-alínea, órgão superior, órgão e unidade gestora (PORTAL DA TRANSPARÊNCIA, 2015f).

Despesa é o compromisso de gasto dos recursos públicos, autorizado pelo Poder a quem o pertence, com o fim de atender a necessidade da coletividade prevista no orçamento. E sua concepção financeira é a aplicação de recursos em forma de gastos e em forma de mutação patrimonial, com o fim de atender as finalidades do estado. Já na concepção econômica é o gasto ou não de dinheiro na realização de serviços para atender às finalidades estabelecidas (MINISTÉRIO DA FAZENDA, 2015a).

A consulta das Despesas no Portal da Transparência do Governo Federal permite aos interessados em acompanhar como o governo emprega os recursos públicos, encontrarem informações diárias e mensais sobre despesas. As informações são detalhadas e diariamente atualizadas, sobre os atos praticados pelas unidades gestoras do Poder Executivo Federal, ao longo da execução das suas despesas. Assim a sociedade pode saber quanto e como estão sendo comprometidos os recursos do orçamento. As informações mensais possibilitam acompanhar os recursos públicos transferidos pela União ao exterior, aos estados e municípios brasileiros, Distrito Federal, instituições privadas e aos cidadãos, e informações mensais referente aos gastos direto do Governo, do Poder Executivo Federal, que permitem a todos conferirem os gastos, como diárias e valores usados por meio do uso de cartões de pagamento (PORTAL DA TRANSPARÊNCIA, 2015b).

Os dados que abastecem as informações disponíveis para consulta são fornecidos pela Secretaria do Tesouro Nacional (STN) e retirados do Sistema Integrado de Administração Financeira do Governo Federal (SIAFI). Portanto, são eles responsáveis pelos registros das informações as unidades gestoras dos órgãos do governo, por serem os executores do orçamento da União (PORTAL DA TRANSPARÊNCIA, 2015c).

As informações que estão disponíveis para consulta da sociedade cumprem o que a LRF determina, ao que dispõe no artigo 48 inciso II da liberação ao conhecimento e acompanhamento, em tempo real, de informações pormenorizadas sobre a execução orçamentária e financeira (BRASIL, 2000). "O equilíbrio dos gastos é muito relevante, no entanto, a prevenção de desequilíbrios fiscais estruturais é preocupação do Estado" (SANTOS, 2002, p.12). 


\subsection{Lei de Responsabilidade Fiscal}

A LRF não trata somente da transparência pública, mas em toda sua redação consta sobre a prestação de contas do Chefe do Poder Executivo que normatiza as contas que deverão ser disponibilizadas aos cidadãos para consulta e apreciação. Defini normas para a escrituração e consolidação das contas públicas, que consistiu na sistematização da consolidação das contas nacionais, inclusive com a fixação de prazos e a cominação de sanções, e outro importante assunto que se refere a previsão de penalidades aos agentes públicos que poderão sofrer sanções de caráter administrativo, civil e penal se cometerem infrações aos dispositivos desta lei (CULAU; FORTIS, 2006).

Estabelece nacionalmente parâmetros a serem seguidos, referente aos gastos públicos de cada ente federativo, estados e municípios brasileiros (SECRETARIA DO TESOURO NACIONAL, 2015). Nesse âmbito, tem objetivo de ajustar as finanças públicas, propor maior transparência nas contas do Governo, por meio de estabelecimento de limites a serem observados para as principais variáveis fiscais, prevê sanções penais para assegurar seu cumprimento, e cria mecanismos que oferecem as condições para cumprir objetivos e metas, e também condições de correção para possíveis desvios que possam ter ocorridos (SANTOS, 2002).

No que tange sobre a Transparência, a LRF incentiva a participação popular em audiências públicas, liberação de informações ao conhecimento e acompanhamento da sociedade de sistema integrado e administração financeira e controle. Trata das normas das finanças públicas na gestão fiscal já prevista na Constituição Federal no artigo 48º que nos deixa claro a intenção de promover a eficácia e eficiência da administração financeira, concedendo assim, para a sociedade, maior acesso as informações. Seus pilares são o Controle, Responsabilidade e a Transparência, quesitos principais para uma boa administração pública (SANTOS; MUNHÃO; TORRES, 2013).

A transparência das contas no poder público tem como base três características: publicidade, compreensibilidade e utilidade. Por isso, conclui-se que não basta apenas divulgar informações, é necessário que elas estejam a disposição em grande escala, de linguagem acessível e boa apresentação. Neste contexto, as informações devem ser disponibilizadas de forma transparente, a divulgação deve estar em conformidade com a compreensão dos dados (GUADAGNIN, 2011). 
A LRF, diz respeito a ampla divulgação, em meios eletrônicos de acesso público, sobre os planos, orçamentos e leis de diretrizes orçamentárias, das prestações de contas e o respectivo parecer prévio, do Relatório Resumido da Execução Orçamentária e o Relatório de Gestão Fiscal e das versões simplificadas desses documentos, assim permiti um avanço na fiscalização da gestão pública ao acesso a informações aos cidadãos (FIGUEIREDO; SANTOS, 2013).

\section{METODOLOGIA}

O estudo foi realizado no município de Tangará da Serra MT, a $240 \mathrm{~km}$ da capital Cuiabá MT - Brasil, com uma população de 83.431 mil habitantes, conforme censo populacional (IBGE, 2010), para que se possa contribuir com as informações relativas ao objetivo da pesquisa no que se refere da participação popular e execução financeira e orçamentária. Os dados para a realização desta pesquisa foram extraídos por meio de acesso constante ao site do município, no período de agosto a outubro de 2015.

Nesta pesquisa, utilizou-se o método de abordagem quantitativo, pois de acordo com Lakatos e Marconi (2010), este é caracterizado por empregar instrumentos, coleta e análise de dados. Desta forma, foi utilizado para averiguar as informações junto ao arquivo municipal e os dados nos sites de divulgação de informações referente a transparência pública de cada município e posterior análise das informações obtidas.

No que tange ao objetivo da pesquisa, é caracterizada como descritiva. A descrição de determinadas características em meio social ou estabelecimento e relações entre variáveis (GIL, 2008). Foi realizado um levantamento telematizado (internet) dos dados divulgados no site da prefeitura, no qual verificou-se as publicações no período de 2010 a 2014 sobre as receitas e despesas.

Com relação ao procedimento técnico, foi documental e estudo de caso, Gil (2008) menciona que pelo uso de materiais ainda não analisados, ou ainda para atender o objetivo da pesquisa se caracteriza como documental. "O estudo de caso é uma modalidade de estudo profundo e exaustivo de um ou poucos objetos, de maneira que permita seu amplo e detalhado conhecimento, tarefa praticamente impossível mediante já considerados" (GIL, 2002, p.54). Devido a verificação e análise de documentos em arquivo público e documentos publicados nos meios eletrônicos, o qual para identificar as receitas e despesas foram utilizados o anexo 01- Quadro demonstrativo da Receita e Despesa segundo as 
Categorias Econômicas e anexo 12 - Balanço Orçamentário e as atas de audiências pública assinadas pelos presentes.

\section{RESULTADOS E DISCUSSÃO}

\subsection{Execução Financeira e Orçamentária}

As informações que atendem as exigências da LRF normalmente são publicadas no Portal da Transparência de cada município. Em Tangará da Serra foram encontradas informações sobre receitas e despesas, porém, as informações sobre receitas que estão disponíveis referem-se de janeiro a dezembro de 2014 e de janeiro a setembro de 2015 e sobre as despesas apenas de janeiro a setembro de 2015.

Tabela 1 - Receitas Arrecadada no ano de 2014 e 2015/valores representados em mil.

\begin{tabular}{l|c|c|c|c|c|c|c|c|c|c|c|c}
\hline Mês & Jan & Fev & Mar & Abr & Mai & Jun & Jul & Ago & Set & Out & Nov & Dez \\
\hline $\begin{array}{l}\text { Rec. } \\
2014\end{array}$ & 13.780 & 11.218 & 12.327 & 18.022 & 12.468 & 10.683 & 13.149 & 13.062 & 12.626 & 12.802 & 12.185 & 13.003 \\
\hline $\begin{array}{l}\text { Rec. } \\
2015\end{array}$ & 13.215 & 12.711 & 13.678 & 13.340 & 18.318 & 16.316 & 13.529 & 12.927 & 12.992 & - & - & - \\
\hline
\end{tabular}

Fonte: Portal da Transparência do município de Tangará da Serra (2015).

No Portal da Transparência é possível a visualização das receitas classificadas e estruturadas em: número da conta, nome da receita, receita prevista, receita arrecadada e receita a arrecadar. E tem a opção de busca rápida, mas que necessita preencher campos: o exercício, mês e tipo da receita, para ver cada receita de forma individual.

Tabela 2 - Despesas no ano 2015/ valores representados em mil.

\begin{tabular}{c|c|c|c|c|c|c|c|c|c}
\hline Mês & Jan & Fev & Mar & Abr & Mai & Jun & Jul & Ago & Set \\
\hline Desp. & 18.765 & 11.904 & 11.617 & 11.203 & 11.717 & 16.530 & 14.897 & 12.149 & 11.270 \\
\hline
\end{tabular}

Fonte: Portal da Transparência do município de Tangará da Serra (2015).

As informações disponíveis sobre as despesas estão classificadas e estruturadas em: código do órgão, órgão orçamentário, código unidade, valor do empenho, valor líquido, valor pago, valor retido, soma/retido e quantidade. E na opção de busca rápida devem ser preenchidos os campos de exercício, data inicial, data final, órgão orçamentário, modalidade e fornecedor.

As informações pormenorizadas devem ser disponibilizadas em tempo real 
(BRASIL, 2000). Em estudo Baracho (2000), ressalta a relevância das informações quando menciona que o município, na prestação de contas, tem que acompanhar outras esferas da administração pública e fornecer informações importantes de gestão contábil, isto é, o conhecimento efetivo da situação patrimonial, financeira e orçamentária do setor público nos seus exercícios e é necessária a adoção de sistemas informatizados integrados, os quais disponibilizem informações em tempo real.

As informações encontradas no portal da transparência do município de Tangará da Serra, não são disponibilizadas em tempo real, somente no trigésimo dia de cada mês. No site da prefeitura deste município, os relatórios são disponibilizados com data de 31 de dezembro de cada ano. Assim, este resultado contraria a pesquisa de Guadagnin (2011) que concluiu em seu estudo que os municípios de Porto Alegre, Canoas e Novo Hamburgo, municípios do Estado do Rio Grande do Sul, cumprem a lei complementar 101/2000 quanto à divulgação em tempo real sobre a arrecadação da receita e execução da despesa.

No site da prefeitura de Tangará da Serra MT, foram encontradas as informações completas e detalhadas, no ícone Contabilidade na opção Contas Públicas - LRF/Balanço Geral, com pastas de arquivos identificadas ao ano correspondente, as quais constam informações sobre as receitas e despesas referentes ao ano de 2010 a 2014 . Dados que são apresentados nas tabelas a seguir.

Tabela 3 - Receitas

\begin{tabular}{l|c|c|c|c|c}
\hline \multicolumn{1}{c|}{ Ano } & 2010 & 2011 & 2012 & 2013 & 2014 \\
\hline Receitulos Correntes & $115.793 .779,89$ & $161.180 .242,97$ & $149.124 .326,25$ & $161.180 .242,97$ & $163.884 .378,35$ \\
\hline -Receitas Tributárias & $17.018 .628,26$ & $26.063 .338,64$ & $21.753 .243,82$ & $26.063 .338,64$ & $33.702 .634,59$ \\
\hline $\begin{array}{l}\text {-Transferências } \\
\text { Correntes }\end{array}$ & $80.203 .788,53$ & $107.523 .484,93$ & $99.499 .722,28$ & $107.523 .484,93$ & $118.571 .801,70$ \\
\hline Receitas de Capital & $3.233 .570,94$ & $4.639 .306,09$ & $5.333 .858,36$ & $4.639 .306,09$ & $5.191 .538,08$ \\
\hline
\end{tabular}

Fonte: Prefeitura Municipal de Tangará da Serra (2015).

Destacam-se as receitas correntes, que tem como subcontas a receita tributária e transferências correntes, e receita de capital. Estas foram escolhidas por representar valores expressivos, conforme tabela 3.

Tabela 4 - Despesas

\begin{tabular}{l|c|c|c|c|c}
\hline Ano & 2010 & 2011 & 2012 & 2013 & 2014 \\
\hline Dítulos & $104.245 .546,07$ & $131.949 .309,91$ & $125.043 .627,63$ & $131.949 .309,91$ & $119.200 .849,92$ \\
\hline
\end{tabular}




\begin{tabular}{l|c|c|c|c|c}
\hline $\begin{array}{l}\text {-Pessoal e Enc. } \\
\text { Sociais }\end{array}$ & $51.498 .799,59$ & $83.664 .876,11$ & $75.012 .546,07$ & $83.664 .876,11$ & $77.699 .047,17$ \\
\hline $\begin{array}{l}\text {-Outras Desp. } \\
\text { Correntes }\end{array}$ & $52.377 .864,30$ & $47.876 .211,22$ & $49.700 .355,87$ & $47.876 .211,22$ & $41.259 .326,74$ \\
\hline Despesas de Capital & $12.586 .436,62$ & $16.781 .753,53$ & $24.889 .848,77$ & $16.781 .753,53$ & $30.668 .133,11$ \\
\hline
\end{tabular}

Fonte: Prefeitura Municipal de Tangará da Serra (2015).

Quanto às despesas, destacam-se as Despesas Correntes que têm as subcontas, despesas de pessoal e encargos sociais, outras despesas correntes, e Despesa de Capital, conforme tabela 4 .

As contas mencionadas nas tabela 3 e 4 são usadas para determinar indicadores relevantes, tais como: Indicadores de suficiência fiscal dos municípios, Indicadores de dependência no financiamento de capital e Indicadores quanto à estrutura das despesas dos municípios (BARACHO, 2000).

As publicações estão divididas em pastas identificadas pelo ano de referência. Os anexos referentes ao ano de 2014 estão na pasta de 2015 e existe a publicação duplicada, ou seja, uma pasta com anexos divulgados em 15 de fevereiro de 2015 junto a outra com data de 14 de setembro 2015, com valores diferentes. Utilizou-se nesta pesquisa os anexos com data de publicação de 14 de setembro 2015, devido estar assinada pelo contador e prefeito.

Nas pastas referentes aos anos de 2013 e 2011, foram encontradas duas publicações de cada ano nas respectivas datas 31 de dezembro de 2013 e 31 de dezembro de 2011. Uma denominada consolidado e outro individualizado (prefeitura), sendo utilizado o consolidado assim como nos outros anos. A publicação referente a 2012, estão na pasta do próprio ano e também na pasta do ano de 2013, mas só estão em duplicidade, porque são documentos idênticos. Os anexos do ano de 2010 estão na pasta correspondente ao seu ano, em publicação única, sendo os anexos publicados com data de 01 de janeiro de 2010.

\subsection{Participação Popular}

No site da prefeitura, no ícone Serviços, na opção Orçamento/Planejamento, encontram-se as pastas de arquivos identificadas ao ano correspondente, as quais constam informações sobre convites, atas de audiências referentes ao ano de 2010 a 2014. As quais estão apresentadas nas tabelas a seguir. 
Tabela 5 - Plano Plurianual.

\begin{tabular}{l|c|c|c|c}
\hline \multicolumn{1}{c|}{ Lei } & Data & Ano de Ref. & População & Participação \\
\hline PPA & $28 / 04 / 2014$ & $2015 / 2017$ & 83.431 & 57 \\
\hline
\end{tabular}

Fonte: Prefeitura Municipal de Tangará da Serra (2015).

O plano plurianual, com vigência de quatro anos, tem o objetivo e prioridades de governo, que existe um elo entre o planejamento e orçamento. A Lei de Diretrizes Orçamentária, com vigência de um ano, possui metas e prioridades de governo, sendo na área fiscal, fomento e tributária (TAZINASSO et al., 2014).

Tabela 6 - Lei de Diretrizes Orçamentaria.

\begin{tabular}{c|c|c|c|c}
\hline \multicolumn{1}{c|}{ Lei } & Data & Ano de Ref. & População & Participação \\
\hline LDO & $28 / 04 / 2014$ & 2015 & 83.431 & 57 \\
\hline
\end{tabular}

Fonte: Prefeitura Municipal de Tangará da Serra (2015).

Na pasta de referência ao ano de 2014, a prefeitura enviou convite para audiência pública de atualização da PPA 2015 a 2017 e LDO 2015, com data de 12 de maio 2014, referente a audiência realizada no dia 20 de maio do mesmo ano, e no dia 11 de maio referente a audiência ocorrida no dia 28 de abril. Os convites foram enviados aos presidentes de conselhos municipais, aos presidentes de associação de bairros, aos secretários municipais, aos vereadores, aos promotores de justiça e aos juízes de direito. Houve também a publicação no diário da serra, jornal local, e publicação no Diário oficial eletrônico dos municípios do Estado de Mato Grosso.

Tabela 7 - Lei orçamentaria Anual.

\begin{tabular}{l|c|c|c|c}
\hline \multicolumn{1}{c|}{ Lei } & Data & Ano de Ref. & População & Participação \\
\hline LOA & $20 / 08 / 2014$ & 2015 & 83.431 & 14 \\
LOA & $26 / 08 / 2014$ & 2015 & 83.431 & 18 \\
LOA & $28 / 08 / 2014$ & 2015 & 83.431 & 18 \\
LOA & $22 / 09 / 2014$ & 2015 & 83.431 & 28 \\
\hline
\end{tabular}

Fonte: Prefeitura Municipal de Tangará da Serra (2015).

A lei Orçamentária anual com vigência de um ano, trata do orçamento fiscal, seguridade social, investimentos, programação financeira e orçamentária, renúncias de receitas e redução da desigualdade social (TAZINASSO et al., 2014).

Na pasta referente ao ano de 2014, há publicação da ata de audiência da LOA com divulgação dos presentes, realizada no dia 22 de setembro de 2014. Foram enviados convites aos presidentes de conselhos municipais, aos presidentes de associação de bairros, aos secretários municipais, aos vereadores, aos promotores de justiça e aos juízes de direito e edital de convocação de audiência pública para apresentação e discussão da proposta 
orçamentária para o exercício financeiro de 2015. Sendo assim, convocou-se toda a população.

Com relação as pastas de conteúdo sobre o PPA, LDO e LOA, referentes aos anos de 2010, 2011, 2012 e 2013, não foram localizadas as atas de presentes nem os convites para as participações nas referidas audiências. Ribeiro (2011), conclui em estudo sobre o nível de publicações dos instrumentos de transparência da gestão fiscal, que existe insuficiência na publicação das informações exigidas pela norma. Assim como nas referidas audiências dos anos mencionados.

Tazinasso et al (2014) relata em sua pesquisa, que por meio de pesquisa realizada pela internet, existem formas práticas de participação da sociedade na elaboração da PPA, LDO e LOA, e ressalta que a internet é uma ferramenta importante na participação dos cidadãos na gestão financeira pública, citando assim, alguns municípios como referência, exemplo o município de Campo Largo-PR, lá o cidadão pode enviar por e-mail e participar das audiências públicas. Em Candeias-BA são entregues formulários aos participantes para proporem ideais de desenvolvimento da cidade e sugestões, que também podem ser enviadas por e-mail. O município de Juazeiro do Norte-CE, a população pode enviar sugestões para as audiências previstas. Em Maceió-AL todas as audiências são transmitidas pela internet em tempo real visando a participação popular e transparência e em Renascença-PR é possível enviar as sugestões por meio do site da prefeitura. O que fica como sugestão ao município de Tangará da Serra adotar tais procedimentos para maior interação e participação com sociedade.

Conforme Prux, Balsan e Moura (2012, p.9) em estudo, mencionam "A falta de participação popular foi preponderante nas atas analisadas, dentre as 18 atas da amostra, 11 não apresentaram tal função agregada". E relata ainda a fala de um deputado que critica a falta de estímulo à participação popular. O que vem de encontro com este estudo, pois a média de participante nas audiências não alcançam $1 \%$ da população.

\section{CONSIDERAÇÕES FINAIS}

Considera-se que o objetivo fora alcançado, visto que o município de Tangará da Serra MT, divulga as informações nos meios de acesso públicos, sobre receitas e despesas, atas de audiências e convites que demostram o incentivo a participação popular. Mesmo que não atenda o período referente ao período de busca no estudo, o município só passou a ter a 
efetiva obrigação em disponibilizar as informações em maio de 2011.

O estudo demonstrou que o município atende parcialmente as exigências que a LRF determina, tendo em vista que o mesmo publica as informações exigidas no que tange as receitas e despesas, porém não atende os Princípios da Transparência, pois as informações não são disponibilizadas em tempo real, não estão claras e de fácil compreensão devido à existência de documentos em duplicidades e valores divergentes. Outro ponto relevante é que os documentos não têm um fácil acesso, já que para a realização desta pesquisa foi necessária a ajuda de funcionários da prefeitura do município para que as informações no site fossem localizadas. E no que se refere as informações sobre a participação popular foram localizadas somente as atas de audiência referente ao ano de 2014.

$\mathrm{Na}$ realização desta pesquisa, algumas limitações foram apresentadas: quanto ao material analisado, alguns não estão disponíveis e a falta de dados pode ter implicado nas informações, conclusões e análises distorcidas, visto que pode indicar o não cumprimento da lei. Para pesquisas posteriores, recomenda-se que seja feito estudos em outras cidades do estado de Mato Grosso, para identificar se estão atendendo a Lei de Responsabilidade, possibilitando assim confrontar os resultados encontrados nesta pesquisa.

\section{REFERÊNCIAS}

BARACHO, M. A. P. A Importância da Gestão de Contas Públicas Municipais sob as Premissas da Governance a Accountability. Revista do Tribunal de Contas do Estado de Minas Gerais. 2000. Disponível em:

<http://200.198.41.151:8081/tribunal_contas/2000/01/- sumario?next=4>. Acesso em: 12 outubro 2015.

BRASIL. Constituição (1988). Constituição da República Federativa do

Brasil: promulgada em 05 de outubro de 1988.

. Lei Complementar $n^{\circ} 101$, de 4 de maio de 2000 (Lei de Responsabilidade

Fiscal). Estabelece normas de finanças públicas voltadas para a responsabilidade na gestão fiscal e dá outras providências.

CONTROLADORIA GERAL DA UNIÃO. Combate à Corrupção e Promoção

da Transparência Pública no Brasil. 2012. Disponível

em:<http://www.cgu.gov.br/Publicacoes/balancos/arquivos/portifolio_cgu.pdf >.

Acesso em: 17 outubro 2015.

CONTROLAdORIA GERAL DA UNIÃO. Páginas de Transparência Pública. 2015. Disponível em: <http://www3.transparencia.gov.br/TransparenciaPublica/>. Acesso em: 20 maio 2015. 
CULAU, A. A.; FORTIS, M. F. A. Transparência e controle social na administração pública brasileira: avaliação das principais inovações introduzidas pela Lei de Responsabilidade Fiscal. In: CONGRESO INTERNACIONAL DEL CLAD SOBRE LA REFORMA DEL ESTADO Y DE LA ADMINISTRACIÓN PÚBLICA, 11., 2006, Ciudad de Guatemala.

Anais. Ciudad de Guatemala: CLAD, 2006. 16 f. Disponível em: <https://bvc.cgu.gov.br/handle/123456789/3235>. Acesso em: 20 maio 2015.

EVANGELISTA, L.; MOTA, C. M. R. Controle social versus transparência pública: uma questão de cidadania. 2010. Disponível em:

<http://portal2.tcu.gov.br/portal/pls/portal/docs/2053966.PDF>. Acesso em: 26 abril 2015.

FIGUEIREDO, V. S.; SANTOS, W. J. L. Transparência e controle social

na administração pública. 2013. Disponível em:

$<$ http://master.fclar.unesp.br/Home/Departamentos/AdministracaoPublica/RevistaTemasde Ad ministracaoPublica/vanuza-da-silva-figueiredo.pdf> Acesso em: 22 maio 2012.

GIL, A. C. Métodos e Técnicas de Pesquisa Social. 6. ed. São Paulo: Atlas, 2008. 2002. . Como Elaborar Projetos de Pesquisa. 4. ed. São Paulo: Atlas,

GONTIJO, V. Orçamento Brasil: instrumento de orçamento e planejamento.

2015. Disponível em: <http://www2.camara.leg.br/atividade-

legislativa/orcamentobrasil/cidadao/entenda/cursopo/planejamento.html>. Acesso em: 14 agosto 2015

GUADAGNIN, A. A transparência na gestão publica: uma análise da sua concretização em Porto Alegre, Canoas e Novo Hamburgo. 2011. Acesso em: <https://www.lume.ufrgs.br/bitstream/handle/10183/34888/000785026.pdf?sequence $=1>$. Acesso em: 26 abril 2015.

HARRISON, T. M.; SAYOGO, D. S. Transparency, participation, and accountability practices in open government: A comparative study. 2014.

Government Information Quarterly, $n^{\circ}$ 31, 2014.

IBGE - INSTITUTO BRASILEIRO DE GEOGRAFIA E ESTATISTICA. Censo da População. 2010. Disponível Em:

<http://cidades.ibge.gov.br/xtras/perfil.php?codmun=510795>. Acesso em: 22 maio 2015.

LAKATOS, E. M.; MARCONI, M. A. Metodologia Científica. 5.ed. São Paulo: Atlas, 2010.

MINISTÉRIO DA FAZENDA. Glossário: Despesa Pública. 2015a. Disponível em: <http://www.fazenda.gov.br/clientes/portalmf/portalmf/glossario>. Acesso em: 31 maio 2015.

Glossário: Receita Pública. 2015b. Disponível em:

<http://www.fazenda.gov.br/clientes/portalmf/portalmf/glossario>. Acesso em: 31 maio 2015. 
NASCIMENTO, E. R.; DEBUS, I. Lei complementar 101/2000: Entendendo a Lei de Responsabilidade Fiscal. 2. ed. 2001. Disponível em:

<http://www3.tesouro.gov.br/hp/downloads/EntendendoLRF.pdf >. Acesso em: 20 outubro 2015.

PORTAL DA TRANSPARENCIA. Dados do Portal. 2015a. Disponível em:

<http://www.portaltransparencia.gov.br/sobre/Origem.asp>. Acesso em: 20 maio 2015.

Despesas. 2015b. Disponível em:

<http://www.portaltransparencia.gov.br/Despesas.asp>. Acesso em: 30 maio 2015

Detalhamento diário das despesas. 2015c. Disponível em:

<http://www.portaltransparencia.gov.br/despesasdiarias/saiba-mais>. Acesso em: 31 maio 2015.

Mais sobre como Fiscalizar. 2015d. Disponível em:

<http://www.portaldatransparencia.gov.br/aprendaMais/Fiscalizar.asp>. Acesso em: 31 maio 2015.

. Perguntas Frequentes: Sobre o Portal. 2015e. Disponível em:

<http://www.portaldatransparencia.gov.br/faleConosco/perguntas-tema-transparencia-leicomplementar.asp\#4>. Acesso em: 21 maio 2015.

. Receitas do governo federal. 2015f. Disponível em:

<http://www.portaltransparencia.gov.br/receitas/SaibaMais.asp>. Acesso em: 30 maio 2015.

. Sobre o Portal. 2015g. Disponível em:

<http://www.portaltransparencia.gov.br/sobre/>. Acesso em: 20 maio 2015.

PORTAL DA TRANSPARENCIA TANGARÁ DA SERRA. Despesas. 2015a.

Disponível

em: <http://177.67.198.34/portaltransparencia/Despesas.aspx>. Acesso em: 12 outubro 2015.

. Receitas. 2015b. Disponível em:

<http://177.67.198.34/portaltransparencia/Receitas.aspx> Acesso em: 12 outubro 2015.

PREFEITURA MUNICIPAL DE TANGARA DA SERRA. Contas Públicas. 2015.

Disponível em: <http://www.tangaradaserra.mt.gov.br/Contas-Publicas/>. Acesso em:

12 outubro 2015

Orçamento e Planejamento. 2015. Disponível em:

<http://www.tangaradaserra.mt.gov.br/Orcamento-Planejamento/>. Acesso em: 12 outubro 2015.

PRUX, P.R.; BALSAN,L. A. G.; MOURA, G. L. Transparência e Participação Popular nas audiências públicas de elaboração e discussão do PPA, LDO e LOA. 2012. 
Disponível em:

$<$ http://www.eumed.net/rev/cccss/22/elaboracion_discusion_ppa_ldo_loa.html $>$. Acesso em: 22 setembro 2015.

RIBEIRO, M. A. Análise das publicações eletrônicas dos instrumentos de transparência na gestão fiscal dos municípios de mato Grosso, sob a perspectiva da Lei de Responsabilidade Fiscal. Revista Brasileira de contabilidade, nº189, Brasília, maiojunho, 2011.

SACRAMENTO, A. R. S. Contribuições da Lei de Responsabilidade Fiscal para o avanço da accountability no Brasil. Cadernos Gestão Pública e Cidadania, v. 10, n. 47, 2005. Disponível em:

<http://bibliotecadigital.fgv.br/ojs/index.php/cgpc/article/view/44042>. Acesso em 20 maio 2015.

SALLES, H. M. Gestão Democrática e Participativa. 2012. 2ed. Disponível em: <http://www.sead.ufba.br/sites/sead.ufba.br/files/gestao_democratica_participativa_gpm_m io lo_online_2edicao.pdf $>$. Acesso em: 13 outubro 2015.

SANTOS, A. S.; MUNHÃO, E. E.; TORRES, A. L. Patrimônio público, gestão e controle com o advento da LRF: Gestão de Matérias Imobilizados no Estado de Mato Grosso.

2013. Disponível em: <http://periodicos.unemat.br/index.php/ruc/article/view/333>. Acesso em: 26 abril 2015.

SANTOS, W. B. A lei de responsabilidade fiscal no contexto da reforma administrativa e os servidores públicos. 2002. Disponível em:

<http://www.pgusp.usp.br/arquivos/artigo_reforma_administrativa_mw.pdf >. Acesso em: 03 maio 2015.

SECRETATIA DO TESOURO NACIONAL. Lei de Responsabilidade Fiscal. 2015. Disponível em: <http://www.tesouro.fazenda.gov.br/pt_PT/lei-de-responsabilidadefiscal>. Acesso em: 03 junho 2015.

SENADO FEDERAL. Portal do Orçamento: Diretrizes Orçamentaria. 2015a. Disponível em: 〈http://www12.senado.gov.br/orcamento/ldo〉. Acesso em: 14 agosto 2015.

. Portal do Orçamento: Plano Plurianual. 2015b. Disponível em: <http://www12.senado.gov.br/orcamento/ppa>. Acesso em: 14 agosto 2015.

. Portal do Orçamento: Orçamento Anual. 2015c. Disponível em: <http://www12.senado.gov.br/orcamento/loa>. Acesso em: 14 agosto 2015.

TAZINASSO, D. et al. Orçamento Público: Elaboração e discussão do PPA, LDO e LOA e as formas de participação Cidadã em suas elaborações. 2014. Disponível em: <http://www.admpg.com.br/2015/index.php?id=89> Acesso em: 22 setembro 2015. 